TRANS · núm. I4 2 2010

DOSSIER $\cdot 25-31$
En los últimos años noventa del pasado siglo y primeros del siglo 21, una de las narrativas más influyentes ha sido la estadounidense, desde el realismo sucio hasta los poderosos escritores posmodernos, como Thomas Pynchon, Don DeLillo y David Foster Wallace, entre otros. En este artículo intentaremos explicar cómo las diferentes traducciones al español de sus libros han contribuido a la apertura de nuevos umbrales para la última narrativa española, y cómo su cosmovisión estética ha proporcionado a los autores españoles nuevos temas, técnicas narrativas, desarrollos de trama y estructuras.

PALABRAS CLAVE: Narrativa norteamericana, traducción creativa, posmodernismo, realismo sucio, imagen.

\title{
Traduciendo narrativa
}

norteamericana: el retorno

a la casa (de los otros)

Translating North-American Narrative: the Return to (others) Home

In the late nineties and the early years of 21st Century, one of the most influential literatures has been the North-American Narrative, from dirty realism to the powerful postmodern writers, like Thomas Pynchon, Don DeLillo and David Foster Wallace, among others. In this article we'll try to explain how the different translations to Spanish of their books has contributed to open new thresholds for Spanish late narrative, and how these aesthetic worldview provided to Spanish authors new themes, narrative techniques,

Vicente Luis Mora

Escritor structures and plot designs.

KEY WORDS: North-american narrative, creative traduction, postmodernism, dirty realism, image. 
TRADUCIENDO NARRATIVA NORTEAMERICANA: EL RETORNO A LA CASA (DE LOS OTROS)

26
Para mí Nueva York es una ciudad de reconocimiento.

\section{Sergio Chejfec}

Desde entonces he regresado varias veces a Nueva York y la sensación es siempre la misma: la certeza de estar volviendo a mi verdadero hogar luego de haber pasado unas vacaciones poco inolvidables en mi ciudad de residencia, llámese Barcelona o Buenos Aires.

\section{Rodrigo Fresán (2004:I93)}

Buena parte de la última narrativa española proviene directamente de modelos anglosajones, sobre todo estadounidenses. Si lanzo esta aserción de modo tan tajante es porque me parece que pocas pueden ser menos discutibles, no sólo por el amplio consenso crítico al respecto $^{\mathrm{I}}$, sino porque - sobre todo- como autor y como crítico literario son los modelos que más continuamente detecto, tanto en la vertiente estructural como en la semántica de las narrativas actuales en castellano. En este sentido, debería puntualizar que hablaré más bien de narrativa española, puesto que la latinoamericana sólo muy tarde ha reconocido de forma abierta su deuda con la narrativa norteamericana; mientras Benet se enorgullecía de su ascendencia faulkneriana, la misma ascendencia

I En un artículo reciente, Fernando Valls dice que entre los autores en otras lenguas «más respetados» por los narradores españoles están «W. G. Sebald,J. M. Coetzee, Cormac MacCarthy, Alice Munro, Lorrie Moore o, entre los más jóvenes, David Foster Wallace» (2009:200); como puede verse, Valls menciona a un alemán, un surafricano que escribe en inglés y cuatro norteamericanos. Extraña la ausencia de Pynchon y DeLillo, sobre los que volveremos a hablar. Véase García Galiano (2004) y García Rodríguez (2009). ha sido considerada como sospechosa si se trataba de Gabriel García Márquez. Un prurito ideológico ha determinado que prácticamente hasta los narradores antologados por Alberto Fuguet y Sergio Gómez en $\mathrm{McOndo}$ (Planeta, Santiago de Chile, I996) no fueran políticamente correctas las asociaciones literarias con el «Imperio» en Latinoamérica. Observemos cómo dos autores incluidos en esa antología critican, con elocuente dureza, el modo en que el miembro del «boom» José Donoso ridiculizaba el modelo cultural estadounidense:

Para justificar su cruel caricaturización del mundo norteamericano, Donoso señala que se trata de ejercer 'nuestro derecho de invadirlos y colonizarlos... y desconocerlos -y, ¿por qué no, vengarnos?- como ellos nos invaden, se apropian de nosotros y nos colonizan'. Toda razón es válida para escribir una novela, incluida la venganza. Pero hay razones más válidas que otras. ¿Para qué combatir un estereotipo de manera negativa, con otro estereotipo? ¿No sería mejor tratar de ir más allá y olvidarnos de golpes bajos? Se trata, después de todo, de hacer literatura, no de cobrar mezquinas cuentas pendientes. (Paz Soldán y Fuguet 2000:I8)

Por ello, citas reconociendo a Nueva York como hogar imaginario, del tono de las arriba recogidas de los argentinos Fresán y Chejfec, sólo han podido leerse en los últimos años. En España, por fortuna, parecía haber mayor libertad para abanderarse y reconocer influencias yanquis, y el hecho sociológico del cambio del idioma francés al inglés como secundario en los planes de estudio, acaecido en torno a I970, provocaría años después una generación de lectores orientados a la literatura anglosajona, entre cuyos miembros aparecerían los escritores últimos. El crecimiento de las traducciones dentro de nuestro sector editorial, que llegan a 
rozar el $30 \%$ de todos los libros publicados en nuestro país ${ }^{2}$, ha contribuido a enriquecer la disponibilidad de lecturas traducidas del inglés, de forma que un buen lector español puede estar leyendo ininterrumpidamente novelas y libros de cuentos estadounidenses durante todo el año, como lo haría un lector californiano. Esta riqueza editorial ha tenido, como veremos, una influencia real en nuestra narrativa, por más que no pueda reflejar-como es natural- la enorme diversidad de propuestas y líneas creativas de la narrativa actual en Estados Unidos. De todas ellas, las tendencias que han llegado a nuestro país podrían ser muchas, pero creo que en los últimos años se han producido dos recepciones principales: la del realismo sucio y la de los narradores de la posmodernidad última y de la «narrativa de la imagen», sobre la que luego volveremos ${ }^{3}$.

\section{EL 'DIRTY REALISM’}

Escribe con razón Eduardo Moga (2007:393) que «el llamado realismo sucio constituye, desde los años 6o, una corriente viva y vigorosa tanto de la narrativa como de la poesía occidentales», en especial -podríamos añadir- en nuestro país ${ }^{4}$. Las líneas estéticas que algunos narradores norteamericanos forjaron durante las últi-

\footnotetext{
2 Según la Federación de Gremios de Editores de España, en 2006 un $28 \%$ de los libros editados fueron traducciones de otras lenguas; cf. http://www.federacioneditores. org/SectorEdit/DatosEstadisticos.asp.

3 Por haber tenido eco, pero menor, nos limitaremos sólo a apuntar que la novela policíaca y el ciberpunk norteamericanos han sido también corrientes de cierta notoriedad en España. Véanse Molinuevo (2006:52ss) y Santamaría (2005).

4 El propio Moga ha estudiado el diverso numeral de poetas españoles influenciados por esta corriente, entre quienes cita a Roger Wolfe, Luis Felipe Comendador, Karmelo C. Iribarren, Manuel Moya, David González y Pablo García Casado.
}

mas décadas del pasado siglo han dejado una alargada sombra en varias narrativas y poéticas, más o menos jóvenes, durante bastante tiempo. Quizá debamos hacer un poco de historia:

en junio de 1983, el crítico norteamericano Bill Buford tituló ‘Dirty Realism' el número ocho de su revista literaria inglesa Granta, anunciando así el nacimiento de una nueva escuela de escritores norteamericanos que, con un estilo realista, pretendían que sus obras arrojaran luz sobre el lado sombrío de la Norteamérica contemporánea. Cuando Buford usó la palabra 'sucio' quería -además de llamar la atención- recalcar que se trataba de un realismo minimalista manchado por la vida, por las pequeñas cosas cotidianas, y en ningún caso pretendió referirse a elemento escatológico alguno. (López Merino, 2005).

La nómina de esta estética ha sido fluctuante, y podría abarcar desde la elegancia post-beat de las Crónicas de motel (1982) de Sam Shepard hasta la prosa limpia y caracterológica de Raymond Carver pasando por la prosa dura y sin concesiones de Charles Bukowski. También en nuestro país la recepción ha sido diversa, como ha señalado Eloy Fernández Porta: «en términos de sociología literaria, la aceptación entusiasta de que gozó esta tendencia en España puede explicarse de la siguiente manera: el dirty realism fue aceptado en virtud de su aura - el aura de desolación y desgracia esencial con marca registrada norteamericana- y de su limpieza, esto es, su indiscutible elegancia formal, su estilo doliente y escueto, su caballerosa manera de retratar la conflictividad suburbana, describiendo frecuentes circunloquios respecto de los temas del sexo, la violencia y la abyección. Simulacro de verismo, por tanto; simulacro de suciedad» (2004:II). Por ese motivo, la nómina local también sería difusa, e incluso podría afectar sólo a algunos libros de algunos 
autores, más que a trayectorias completas. Con posterioridad, según Juan Fernando Merino (2002:II), el realismo sucio habría dejado paso ambientada en la desestructuración familiar (Lorrie Moore, la canadiense Alice Munro), aunque a nuestro juicio es más interesante $-\mathrm{y}$ muy influyente en nuestro país- la línea de la que hablaremos a continuación.

\section{EL POSMODERNISMO TARDÍO O NARRATIVA DE LA IMAGEN}

Mientras que el realismo sucio tiene ya una dinámica crítica bien asentada ${ }^{5}$, nos encontramos con el problema de que falta por hacer toda una historia de la amplísima recepción que la novela posmoderna última norteamericana y lo que hemos llamado en otro lugar narrativa de la imagen (Mora, 2006:275-304) han tenido en la narrativa actual española, sobre todo en la más joven.

Cuando los fenómenos a estudiar son muy recientes, y teniendo en cuenta que la academia gusta de guardar un largo período de respeto hacia los hechos antes de examinarlos, pueden ayudarnos en este tema (amén de las intuiciones, declaraciones expresas y análisis críticos de urgencia), algunas manifestaciones que tienen lugar en el campo literario español, en cuanto expresiones de tensiones, líneas de fuga y tendencias. En este sentido, y a modo casi anecdótico, baste decir que se han creado recientemente en la red social Facebook dos grupos que resultan interesantes a nuestros propósitos explicativos. Uno de ellos se llama "Quiero que traduzcan House of Leaves de Mark Danielevski», y otro "Leo todas las traducciones de Javier Calvo en Mondadori». Ambos

5 Además de los estudios citados, véanse Lozano Mijares (2007:225-26) e Izquierdo (2001:293-308).

tienen cerca de cuarenta miembros, entre los que se cuentan narradores, críticos literarios y personas del mundo de la literatura española. Si la existencia de ambos por separado es de por sí bastante significativa, la lectura conjunta da mucho que pensar: significa que la literatura norteamericana que interesa a los narradores españoles es tan compleja que, a pesar de leer inglés, necesitan de una traducción guía, de un Virgilio de la lengua que les abra las puertas a una comprensión total de la obra, un Ellmann que aclare las oscuridades de los nuevos Ulysses (puesto que House of Leaves no tiene la calidad de la novela de Joyce, pero sí es comparable en su dificultad de acceso, sustituyendo las complejidades lingüísticas por las lingüísticovisuales). Creo que la recepción de la literatura del desaparecido David Foster Wallace habla por sí sola a este respecto. Wallace ha sido, de lejos, el escritor más influyente para un gran y muy diverso grupo de narradores nacidos en los años 60 y 70 del pasado siglo. Amén de la cita en nota que hacíamos antes de Fernando Valls, podemos recordar el número homenaje que la revista Quimera dedicó tras la muerte del escritor neoyorkino en enero del 2008, donde colaboraban con textos sobre Wallace prosistas como Ricardo Menéndez Salmón, Juan Francisco Ferré, Juan Trejo, Manuel Vilas, Robert Juan-Cantavella, Agustín Fernández Mallo, Germán Sierra o Eloy Fernández Porta. En la presentación del dossier escribía Trejo que «para la siguiente generación (...) descubrir a DFW supuso, casi de manera generalizada a pesar de lo individual, una conmoción. DFW hablaba de algo que entendíamos sin ni siquiera habernos detenido aún a pensar sobre ello, y lo hacía de un modo que nos resultó novedoso e iluminador, a pesar de su aritmética complejidad» (2008:29). Aclarando que con esa «generación» se refiere Trejo a los ya citados como 
nacidos en los años sesenta y principios de los setenta, fijémonos en tres elementos incluidos en esa frase: individualidad, conmoción, dificultad. A pesar de la diversidad de la recepción, había en casi todos los autores mencionados algo en común: la mayoría tuvieron acceso a los textos de Wallace a través de las traducciones de Calvo, incluso aquellos que dominaban el inglés y que querían (o queríamos) tener una buena versión de referencia para examinar el modo en que aquello podría llegar al castellano y construirse como lengua narrativa propia.

Siguiendo (por una vez y sin que sirva de precedente) los esquemas jakobsonianos, el problema que tenía la traducción de Wallace o de otros narradores de la imagen era que la castellanización no sólo debía ser interlingual, sino también intersemiótica. Como ya decía Alexander F. Tytler en su Essay of the Principles of Translation (I790), al definir una buena traducción como aquella que transmite por completo de la obra original a otra lengua, de forma que sus hablantes nativos lo perciben con la misma claridad y lo sienten con idéntica fuerza que los que hablan la lengua de la obra original, esta narrativa tan literaria y tan visual a la vez necesitaba de un narrador cultivado en los mismos imaginarios audiovisuales, conocedor de las referencias, lector de los mismos patrones literarios que Wallace (Barth, Gass, Gaddis, Pynchon, DeLillo), y propietario él mismo de una lengua narrativa propia de su tiempo. Su «libertad vigilada» ${ }^{6}$ debía ensanchar el campo literario de los lectores, y eso fue lo que ocurrió,

6 «Se puede decir que el traductor es un productor en libertad vigilada: debe reproducir el semiotopo del texto fuente modificándolo al mínimo, y debe respetar las exigencias peculiares de la lengua con la que escribe un nuevo texto. Son exigencias a menudo contradictorias, y todo el arte del traductor consiste en armonizarlas» (Ezquerro, 2008:3I). dotando a todo un amplio grupo de narradores y narradoras españoles de una panoplia de recursos técnicos que constituyen referencias inexcusables. Algo así le pasó, como es natural, al propio Calvo: su relato "Arco iris de levedad», incluido en Risas enlatadas (200I), debe menos al Gravity's Rainbow de Pynchon que al cuento "Animalitos inexpresivos» de Wallace, que abría La niña del pelo raro (1989), traducido por él: ambos textos comparten tema (directivos y presentadores de televisión), y modo "cámara» de afrontar la composición estructural del texto; cada párrafo es una «toma» y cada escena está descrita y transcrita como lo haría una serie televisiva. Este modo de narrar, autoanalizado por Wallace en su fantástico ensayo, «E unibus pluram» 7 , ha tenido una larguísima descendencia hasta nuestros días, siendo climática a este respecto la reciente novela de Jorge Carrión, Los muertos (20I0). Un tipo de narrativa que, por lo demás y como apunta Ferré, habría intentado precisamente superar el modelo anterior de realismo sucio: «esta novela terminal procedería a liquidar todas las herencias (la del modernismo y el posmodernismo tanto como la de diversos realismos, más o menos sucios)» (2008:33). Otro factor relevante en este proceso, que no corresponde tratar aquí pero sí dejar al menos apuntado, sería el papel de la editorial Mondadori, que ha publicado no sólo la mayoría de los libros de la narrativa norteamericana de la imagen, incluyendo todas las traducciones de Wallace, sino también la mayoría de novelas y libros de

\footnotetext{
7 «Nuestras seis horas diarias no solamente nos ayudan a sentirnos íntimos y personales con cosas como los Juegos Panamericanos o la Operación Escudo del desierto, sino que, a la inversa, también nos enseñan a relacionarnos con personas vivas y reales de la misma forma en que nos relacionamos con lo distante y exótico, como si estuvieran separados de nosotros por la física y el cristal, solamente, existentes únicamente como espectáculos que esperan que los miremos desde lejos» (Wallace, 200r:82).
} 
cuentos de prosistas españoles influenciados por esa línea norteamericana.

\section{EL HILO TRADUCCIÓN-CREACIÓN}

Por lo tanto, hay una relación muy directa entre las traducciones de narrativa norteamericana, en especial las realizadas por Calvo, y la última narrativa española. Los nombres de Pynchon (muy presente en la obra de Eduardo Lago), Wallace (en los autores ya mencionados y en Jon Bilbao ${ }^{8}$ ), DeLillo, Roth, Mailer, Irving ( J. M. de Prada), Cheever (Eloy Tizón, Rodrigo Fresán), Hammet y Chandler ${ }^{9}$, Hunter S. Thompson (Juan-Cantavella), Alice Munro y Lorrie Moore (Diego Doncel) o Franzen (Luis Manuel Ruiz) por no remontarnos a Jack London (Belén Gopegui), Lovecraft (Ferré) o Edgar Allan Poe (Juan Bonilla, David Roas, Edgar Borges y muchos otros relatistas), son claves para entender ciertos modos de construir las historias, y cierta forma muy visual de describirlas. El hecho mismo de la traducción, por la familiaridad de uso, se vuelve muy útil como material constructor. A este efecto podríamos citar el inteligente relato "Los dos monstruos» de Enrique Prochazka en Único desierto (1997), montado en tres tablillas que cuentan la misma historia de distinta forma o «lengua» (como la piedra Rosetta, antecedente de cualquier traducción), y «Hacia una traducción de Gigamesh de Patrick Hannahan» de Javier Fernández en La grieta (2007), que trae causa a su vez del delirante prólogo de Stanislaw Lem a la novela

\footnotetext{
8 Cf. http://www.aviondepapel.tv/2009/o4/jonbilbao-antes-despues-escritura/.

9 Hablando de literatura negra, escribe Gonzalo Navajas que «la novela española de las dos últimas décadas, siguiendo en ello el modelo de la novela clásica de misterio americana (Dashiell Hammett, Raymond Chandler), inserta consideraciones éticas» (Navajas, 1998:25).
}

apócrifa «Gigamesh» en Vacio perfecto (1972). Fernández es él mismo traductor de literatura inglesa (Ballard, Golding) y por ello su irónica reflexión sobre el hecho traductor es muy significativa. Varios relatos actuales, como el «Relato pop» de Eloy Fernández Porta (200r:95ss), se presentan como traducciones irreverentes o infieles de textos anteriores (en este caso, de una también hipotética hermana del autor), en un juego donde el cuestionamiento posmoderno de las ideas de autoridad, responsabilidad textual y juegos de referencias es el eje constructivo del cuento. Por lo demás, este juego narrativo sólo continúa una larga tradición escrituraria cuyos antecedentes pueden remontarse a Cervantes y Potocki ${ }^{\text {Io. }}$.

\section{CONCLUSIÓN}

La conclusión de todo lo expuesto anteriormente no es lo que este párrafo dice, sino el mismo estado de cosas de parte de la narrativa española actual. Que los más jóvenes estén particularmente afectados por ella no significa que los escritores de mayor edad no se hayan sentido aludidos por la narrativa estadounidense: pensemos en el caso paradigmático de Benet con Faulkner, por poner un ejemplo canónico. La casa de otros ha terminado por ser también la casa propia, donde se han refugiado sucesivas promociones de escritores en busca de panoramas más anchos, animados por la falta de referentes incuestionables en la tradición española ${ }^{\mathrm{II}}$.

ıo Véase el libro de H. C. Hagedorn La traducción narrada, donde también se citan también casos más recientes, como las novelas Cielos de la tierra, de Carmen Boullosa, o Si una noche de invierno un viajero, de Italo Calvino, así como otras obras de «Borges, Schmidt, Cabrera Infante, García Márquez, Wouk y Jacobson» (Hagedorn, 2006:205).

II Con esto no queremos decir que no hubiera modelos narrativos literariamente incuestionables (entre los que destacaríamos a Cela, Benet, Espinosa, Julián Ríos, 
Por ello pensamos que reunir a tres traductores de edades muy diferentes podría darnos una imagen cabal de los procesos sociolingüísticos que acarrea la traducción literaria, adaptados al caso estadounidense. Desde el sabio narrador Ramón Buenaventura al joven y dotado Calvo pasando por la luminosidad de Isabel Núñez, las distintas y poliédricas experiencias y perspectivas de traducción salen a la luz y, sea desde visiones más teóricas o abstractas, sea desde la explicitación de casos concretos (como el de Buenaventura con Franzen), el resultado es un mosaico variado del modo en que la narrativa norteamericana ha sido descodificada primero para codificarse después en narrativa traducida, dispuesta a retroalimentar la narrativa española, siempre atenta a la evolución del mercado literario estadounidense.

RECIBIDO Y VERSIÓN FINAL: ENERO DE 2010 ACEPTADO: FEBRERO DE $20 I O$

\section{REFERENCIAS BIBLIOGRÁFICAS}

Ezquerro, M. (2008). Leerescribir; Rilma $2 /$ ADEHL; México D.F. / París.

Fernández Porta, E. (2004). «Golpe por golpe», en E. F. Porta y Vicente Muñoz Álvarez (eds.), Golpes. Ficciones de la crueldad social; DVD, Barcelona.

Fernández Porta, E. (20oI). «Relato pop», Caras B (de la música de las esferas); Debate, Barcelona.

Ferré, J. F. (2008). «El cadáver exquisito de W», Quimera $\mathrm{n}^{\mathrm{o}} 3 \mathrm{O2}$, enero, p. 33.

Fresán, R. (2004). «Apuntes para una teoría de King Kong y sus alrededores», Granta en español, $\mathrm{n}^{\circ}$ 2, verano/otoño, p. I93.

García Galiano, A. (2004). El fin de la sospecha; Universidad de Málaga, Servicio de Publicaciones, Málaga.

García Rodríguez, J. (2009). «Border lines/border lies:

Torrente Ballester y Juan Goytisolo), sino que diversas circunstancias editoriales, biográficas, o personales impidieron que lo fueran. algunos ejemplos de la nueva narrativa española»; Ínsula $\mathrm{n}^{\circ} 754$, octubre.

Hagedorn, H. C. (2006). La traducción narrada: el recurso narrativo de la traducción ficticia; Universidad de Castilla La Mancha.

Izquierdo, J. M. (200I). «Narradores españoles novísimos de los años noventa», Revista de Estudios Hispánicos, Washington University, n. ${ }^{\circ}$ 2, tomo xxxv, 99, 293-308.

López Merino, J. L. (2005). «Sobre la presencia de Roger Wolfe en la poesía española (I990-2000) y revisión del marbete "realismo sucio»", Espéculo, $\mathrm{n}^{\mathrm{o}}$ 3I.

Lozano Mijares, M. P. (2007). La novela española posmoderna; Arco Libros, Madrid.

Merino, J. F. (ed.). (2002). Habrá una vez. Antología de cuento joven norteamericano; Alfaguara, Madrid.

Moga, E. (2007). Lecturas nómadas; Candaya, Barcelona.

Molinuevo, J. L. (2006). La vida en tiempo real. La crisis de las utopias digitales; Biblioteca Nueva, Madrid.

Mora, V. L.: (2006). «Post/posmodernidad?: narrativa de la imagen, next-generation y razón catódica en la narrativa contemporánea», en Javier Gascueña Gahete y Paula Martín Salván (eds.), Figures of Belatedness: Postmodernist Fiction in English; Servicio de Publicaciones de la Universidad de Córdoba, Córdoba.Paz Soldán, E. y Fuguet, A. (2000): «Prólogo», a Edmundo Paz Soldán y Alberto Fuguet (eds.), Se habla español; Alfaguara, Miami.

Navajas, G. (I998). «El icono verbal roto: la narración de la estética finisecular», en Irene Andrés-Suárez (ed.), Mestizaje y disolución de géneros en la literatura hispánica contemporánea; Verbum, Madrid.

Santamaría, A. (2005). El idilio americano. Ensayos sobre la estética de lo sublime; Ediciones Universidad de Salamanca.

Trejo, J. (2008). «DFW y la delgada línea roja», Quimera $\mathrm{n}^{\circ} 302$, enero, p. 29.

Valls, F. (2009). «Entre sólida y líquida: la prosa narrativa española», en Jordi Gracia y Domingo Ródenas de Moya, Más es más. Sociedad y cultura en la España democrática, 1986-2008; Vervuert Iberoamericana, Madrid.

Wallace, D. F. (200I). "E unibus pluram», en Algo supuestamente divertido que nunca volveré a hacer; Mondadori, Barcelona. 